\title{
Spike developmental stages and ABA role in spikelet primordia abortion contribute to the final yield in barley (Hordeum vulgare L.)
}

Faiza Boussora ${ }^{1,3,4}$, Mohamed Allam ${ }^{1,7}$, Ferdaous Guasmi ${ }^{3}$, Ali Ferchichi ${ }^{5}$, Twan Rutten ${ }^{1}$, Mats Hansson ${ }^{6}$, Helmy M. Youssef ${ }^{1,2,6^{*}}$ (D) and Andreas Börner ${ }^{\text {* }^{*}}$

\begin{abstract}
Background: Salinity is a significant environmental stress factor limiting crops productivity. Barley (Hordeum vulgare L.) has a natural tolerance to salinity stress, making it an interesting study object in stress biology research. In the present study, for the first time the effect of salinity stress on barley inflorescence developmental stages was investigated. Five spring barley genotypes irrigated with saline water $(12.5 \mathrm{ds} / \mathrm{m} \mathrm{NaCl})$ were compared to controls treated with normal tap water. We measured abscisic acid (ABA) concentrations in the apical, central and basal sections of the immature inflorescence at green anther (GA) stage. The role of ABA in spikelet primordia development, atrophy and abortion and final yield was evaluated.
\end{abstract}

Results: A time course experiment starting from double ridge until green anther (GA) stages revealed that salinity reduced the length of spike developmental stages in all genotypes causing shortened of the plant life cycle. The shortened plant life cycle negatively affected plant height and number of tillers/plant. Salinity also affected spikelet primordia development. In both control and salinity treated plants apical spikelet abortion started in late awn primordium (AP) stage. However, under salinity treatment, significantly more spikelets were aborted, thus directly affecting plant yield potential. ABA, which plays a role in the spikelet/floret abortion process, was markedly elevated in the base and apex of salt treated spikes correlating with an increased spikelet abortion in these regions.

Conclusions: Overall, salinity treatment reduced all plant and yield-related parameters investigated and turned some of the correlations among them from positive to negative or vice versa. Investigations of ABA role in floral development and phase duration of barley spike showed that, ABA regulates the spikelet/floret abortion process affecting the yield potential under salinity and control conditions.

Keywords: Barley, Salinity, ABA, Spike development, Primordia abortion, Spikelet/floret abortion

\section{Background}

Abiotic stresses due to salinity occurs naturally (Dai 2011) but has become a growing global problem due to human activities such as salt mining (Ghassemi et al. 1995) and poor irrigation systems (Marcum and Pessarakli 2006). At present more than 800 million hectares of agricultural land are affected by salinity and/or

\footnotetext{
*Correspondence: Youssef@ipk-gatersleben.de; helmy.youssef@biol.lu.se; boerner@ipk-gatersleben.de

${ }^{1}$ Leibniz Institute of Plant Genetics and Crop Plant Research (IPK),

Corrensstraße 3, 06466 Gatersleben, Germany

Full list of author information is available at the end of the article
}

sodicity stress (Munns 2005; Farooq et al. 2015). In arid and semiarid countries, agricultural production is limited by water availability and the resources of water are insufficient for the growing human population. As fresh water is allocated in priority for drinking purposes, irrigation water is often of poor quality. Nowadays, it has been estimated that about $20 \%$ of the cultivated land worldwide is affected by salinity (Jamil et al. 2011). The corresponding proportion of irrigated agricultural land is $33 \%$, expected to reach $50 \%$ of the arable land by the year 2050 (Jamil et al. 2011). The growing salinity problem in arid and semi-arid regions needs an urgent 
solution where research aiming to understand the effects of salinity on cereals production should be combined with genetic efforts to develop salt tolerant crops for the future of agriculture (Shannon 1984; Owens 2001; Kausar et al. 2013). Biochemical pathways, morphological and physiological processes including seed germination, growth and development are affected by salinity (Willenborg et al. 2004) causing yield and quality reduction (Basalah 2010; Bagues et al. 2018). However, plant species differ in their response to salinity stress (Torech and Thompson 1993; Sarabi et al. 2017).

Barley (Hordeum vulgare L.) is one of the oldest cereal crops known to be cultivated since about 10,000 years. It has a natural tolerance to drought and salinity stresses. The inflorescence of cultivated barley is an indeterminate spike that produces three singleflowered spikelets at each rachis internode that make it unique among the grasses. Barley row type varies from two-rowed to six-rowed and is controlled by at least five independent mutant loci that include sixrowed-spike1 (vrs1), vrs2, vrs3, vrs4, and Intermedium-c (Int-c). These loci are located on barley chromosomes 2HL, 5HL, 1HS, 3HS and 4HS, respectively (Pourkheirandish and Komatsuda 2007). The yield production is controlled by number of tillers (side shoots) and number of spikelets per spike and both are negatively correlated to each other. Spike developmental and growth stages (Fig. 1) play a very important role in defining the seed yield. Therefore, improved grain yield through enhanced spikelet survival is a key objective of many cereals breeding programs (Alqudah and Schnurbusch 2014). The maximum yield potential per spike is represented by the number of spikelets per spike at the awn

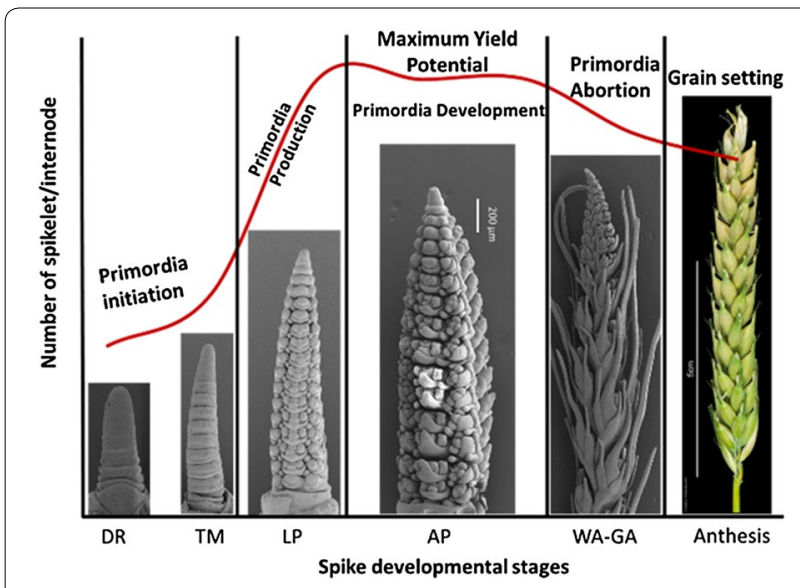

Fig. 1 The spikelet primordia initiation, growth and development, abortion and grain setting phases in barley. $D R$ double ridge, $T M$ triple mound, LP lemma primordium, AP awn primordium, WA white anther, GA green anther primordium stage (Riggs and Kirby 1978; Waddington et al. 1983; Kirby and Appleyard 1987; Kernich et al. 1997; Alqudah and Schnurbusch 2014).

At the awn primordium stage six-rowed barley displays more spikelets/florets primordia per spike than tworowed barley (Whingwiri and Stern 1982; Kirby and Appleyard 1987; Kernich et al. 1997; Miralles et al. 2000; del Moral et al. 2002; Arisnabarreta and Miralles 2006). Inflorescence development and growth, phase duration and organ patterning are influenced by phytohormones such as auxin (IAA), cytokinin (CK) and abscisic acid (ABA) (Su et al. 2011; Matsoukas 2014; Youssef et al. 2017). $\mathrm{ABA}$ also is the primary hormone that mediates plant responses to stress such as drought and salinity (Wu et al. 1997; Wilkinson and Davies 2010; Lee and Luan 2012). It has been suggested that the ABA level correlates with the plant resistance to stress (Maslenkova et al. 1993; Lee and Luan 2012) including salinity stress (Nilsen and Orcutt 1996; Suzuki et al. 2016). ABA is supposedly involved in the induction of the synthesis of the $26-\mathrm{kDa}$ protein Osmotin which accumulation depends on the presence of $\mathrm{NaCl}$ (Bressan et al. 1985). ABA may also influence stomatal conductivity affecting tissue hydraulics (Collins and Kerrigan 1974; Davies and Zhang 1991; Freundl et al. 2000; Hose et al. 2002; Du et al. 2013) growth in response to drought or salinity through changes in cell wall extensibility (Bacon 1999; Cramer et al. 1998; Dodd and Davies 1996; Thompson et al. 1997) and apoplastic $\mathrm{pH}$ in plants (Bacon et al. 1998). Other studies have focused on the effect of ABA accumulation and a decrease in IAA and $C K$ on the progression of senescence in salinized plant organs (Albacete et al. 2008; Ghanem et al. 2008). Salinity affects both vegetative and reproductive developmental stages and reduces shoot growth and the number of florets per ear. Furthermore, salinity increases sterility and changes the time of flowering and maturity in grasses (Läuchli and Epstein 1990). In the present work we studied the response of inflorescence developmental stages, spikelet primordia development, and ABA concentrations in the inflorescence of five spring barley genotypes to salinity stress and related this to final yield.

\section{Materials and methods Plant material}

Five six-rowed spring barley genotypes, Ardhaoui, Kounouz, Lemsi, Manel and Rihane, maintained at the Tunisian gene bank were selected for this study based on their importance and yield under stress conditions (Table 1).

\section{Growing conditions and salinity treatment}

The five barley genotypes were grown in IPK-Gatersleben greenhouse under long day conditions $16 \mathrm{~h} / 8 \mathrm{~h}$ (day/ night) and temperature of $\sim 20 \pm 2{ }^{\circ} \mathrm{C}$ during the day and 
Table 1 Names, year of release and characteristics of the barley genotypes studied (Chaabane et al. 2009; Ben Ghanem and El Felah 2011; Ben Youssef et al. 2011)

\begin{tabular}{llll}
\hline Name & Year of release & Characteristics & Yield (t/ha) \\
\hline Ardhaoui & Local Tunisian variety & Adapted to the driest regions & $\approx 4.5$ \\
Kounouz & Selected by INRAT in 2011 & Resistance to fungal diseases & $\approx 5.2$ \\
Lemsi & Selected by INRAT in 2009 & Used as fodder & $\approx 4.0$ \\
Manel & Selected by INRAT in 1996 & Suitable for wetlands & $\approx 5.5$ \\
Rihane & Introduced from ICARDA in 1982 & Adapted to semi-arid regions & $\approx 5.0$ \\
\hline
\end{tabular}

INRAT Institut National de Recherche Agronomique de Tunis, ICARDA International Center for Agriculture Research in the Dry Areas

$\sim 16 \pm 2{ }^{\circ} \mathrm{C}$ during the night. Per genotype two sets of 96 seeds were germinated in 96 wells plates, one watered with tap water as control and the second treated with saline water $(12.5 \mathrm{ds} / \mathrm{m} \mathrm{NaCl}$, selected based on preliminary where the plants died at more than $12.5 \mathrm{ds} / \mathrm{m} \mathrm{NaCl}$ concentration) starting from the day of planting. When seedlings reached three leaves stage, they were transferred into $14 \mathrm{~cm}$ diameter pots, irrigated with either tap water or saline water. Agricultural practices were performed as recommended, including pest, disease and weed control.

\section{Plant and spike phenotyping}

To establish spike developmental stage, every second day after transfer into $14 \mathrm{~cm}$ pots, two plants of each genotype were dissected under a stereomicroscope (Stemi 2000-c, Carl Zeiss Micro Imaging GmbH, Gottingen, Germany). To compare spike developmental under salinity stress with control conditions, spikes of five or more plants at the developmental stages: Double Ridge (DR), Triple Mound (TM), Glum Primordia (GP), Stamen Primordium (SP), Lemma Primordium, Awn Primordium (AP), White Anthers (WA) and Green Anthers (GA) according to Kirby and Appleyard (1987), were collected for electron micrographs. After anthesis ten control and ten salinity treated plants were scored for plant height, number of tillers and main spike length. After complete maturity all spikes from each plant were collected for yield. Yield-related parameters seed length, seed width, seed area, number of seeds/plant, plant seeds weight and 1000-Grain weight) were measured. The experiment was repeated three times in the same green house under the same conditions.

\section{Scanning electron microscopy (SEM)}

For SEM analysis, isolated barley spikes were fixed with $4 \%$ formaldehyde in $50 \mathrm{mM}$ phosphate buffer, $\mathrm{pH} 7.0$ for $16 \mathrm{~h}$. After dehydration in a graded ethanol series and critical point drying in a Bal-Tec critical point dryer (BalTec AG, Balzers, Switzerland), spikes were gold sputtered in an Edwards S150B sputter coater (Edwards High
Vacuum Inc., Crowley, West Sussex, UK) and examined in a Hitachi S-4100 SEM (Hisco Europe, Ratingen, Germany) at $5 \mathrm{kV}$ acceleration voltage. Digital recordings were made and stored as Tiff-image files.

\section{ABA determination}

To compare ABA concentration along the developing spike, of each genotype 12 to 16 spikes at GA stages were collected and sectioned into basal, central, and apical parts (Youssef et al. 2017). After freeze-drying 20 to $50 \mathrm{mg}$ dry weight was used to extract $\mathrm{ABA}$ according to Kojima et al. (2009) and Seo et al. (2011). ABA analysis by GC/MS (Shimadzu GC 2010 A chromatograph) was performed as described in Okamoto et al. (2009). Data from four biological replicates were analyzed and significance values were calculated.

\section{Statistical analysis}

The experiment was arranged as a completely randomized design with ten replicates per genotype per treatment (control and salinity). Main effects of genotypes, control and salinity treatments, along with the corresponding interactions were tested using two-way analysis of variance (ANOVA). Significance of differences between means was estimated with Tukey's HSD (Honest Significant Difference test). Pearson correlation coefficients for pairwise comparisons between all traits were computed. All statistical analyses in this study were conducted using R 3.5.3 (R Core Team 2018).

\section{Results}

Effect of salinity treatment on plant height and number of tillers

Five six-rowed spring barley genotypes, Ardhaoui, Kounouz, Lemsi, Manel and Rihane, were grown with or without salt. Even under control conditions the barley genotypes tested differed significantly with regard to plant height and number of tillers (Fig. 2). Plant height and number of tillers/plant were highest in the genotypes Ardhaoui and Rihane. These values were significantly smaller in the other three genotypes with the by far 


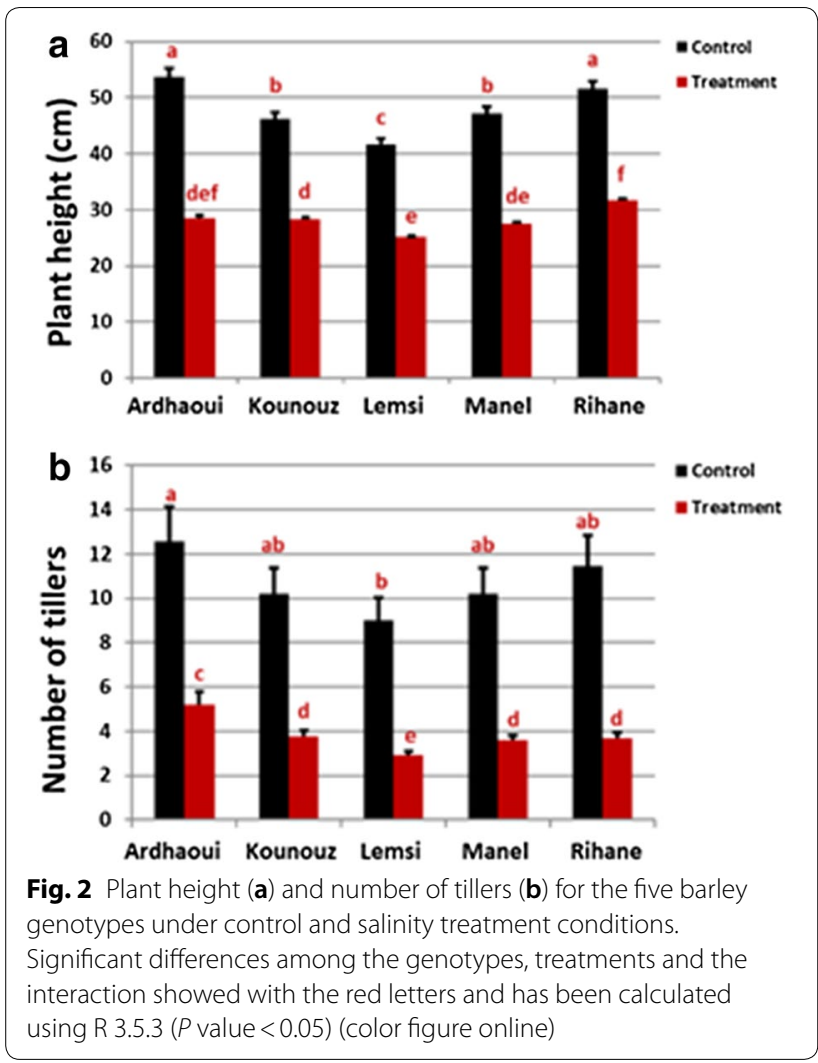

lowest values found in the genotype Lemsi (Fig. 2). The salinity treatment caused a substantial reduction in both plant height and number of tillers in all genotypes (Fig. 2, Additional file 1: Fig. S1). Under salinity plant height was largest in the genotype Rihane and lowest in the genotype Lemsi. For number of tillers/plant highest values were found in the genotype Ardhaoui, lowest again in the genotype Lemsi (Fig. 2).

\section{Salinity affects the length of spike developmental stages}

The duration from planting to each of the eight developmental stages were measured for the five barley genotypes. When grown under control conditions, no differences were found between the genotypes from the double ridge (DR) stage to/through the white anther (WA) stage except for the Lemsi genotype (Fig. 3a). Lemsi not only developed faster but also reached flowering (heading day, HD) earlier than the four other genotypes (Additional file 2: Table S1). The other four genotypes started to diverge from each other after the WA stage. While genotype Manel reached green anther (GA) and heading (HD) stage at 44 and 52 days after planting (DAP), respectively, these values were 45 and 54 DAP for the genotype Kounouz, 48 and 58 DAP for the genotype Ardhaoui, and 51 and 62 DAP for the genotype Rihane (Fig. 3a and Additional file 2: Table S1). Stronger differences between the genotypes were seen under salinity treatment. Starting from Lemma Primordium (LP) stage, all genotypes reached subsequent spike developmental stages faster under salinity treatment than under control conditions (Fig. 3b). The shortest stage lengths for LP-AP, AP-WA, WA-GA and GA-HD were recorded for the Lemsi genotype taking 3, 6, 6 and 3 days, respectively (Fig. 3b). Consequently the Lemsi genotype was also the earliest to reach heading (33 DAP). The genotypes Ardhaoui, Kounouz and Manel reached heading at 45, 43 and 44 DAP, respectively. With LP-AP, AP-WA, WA-GA and GA-HD lasted 4, 11, 10 and 9 days, respectively (Fig. 3b), stage length reduction compared to control conditions was least severe in genotype Rihane which was the last to reach heading at 54 DAP.

\section{Salinity reduces the yield potential}

Scanning electron micrographs from DR to GA showed a clear effect of salinity on the spikelet primordia development. In the early stages from DR to AP, no obvious difference between the control and salinity conditions was found. In both control and salinity treated plants an atrophy of the basal and apical spikelets became evident from late AP stage onwards (red stars in Fig. 4). The number of aborted spikelets, however, was significantly higher under salinity treatment thus directly affecting plant yield potential. Spikelet abortion was more substantial in the apical part than in the basal part of the spike (Fig. 4).

\section{Salinity affects $A B A$ concentration in the immature spike} Reports of local ABA accumulation in response to salinity stress (Wu et al. 1997; Suzuki et al. 2016) and observed spikelet atrophy at the apical and the basal sections of the spike at the GA stage (Fig. 4), called for a study on the differences of $\mathrm{ABA}$ concentrations along the spike at this stage. The results revealed that salinity caused an overall increase in the ABA concentrations within the spike. As under control conditions, however, ABA were always highest in the apical section and lowest in the central section of the spike. Among the barley genotypes ABA concentration under both control and salinity condition was highest in the salinity sensitive genotypes Lemsi and Manel (Fig. 5). The enhanced concentration of ABA and a concurrent increase in spikelet abortion under salinity (Fig. 4b) thus underlines the role of ABA in abortion phenomena.

\section{Effect of salinity treatment on yield traits}

The effect of salt treatment on yield traits and their correlations of the five tested barley genotypes are shown in Additional file 3: Table S2 and Fig. 6. The data showed a clear reduction of all yield-related parameters investigated, i.e. spike length, seed length, seed width, seed area, 


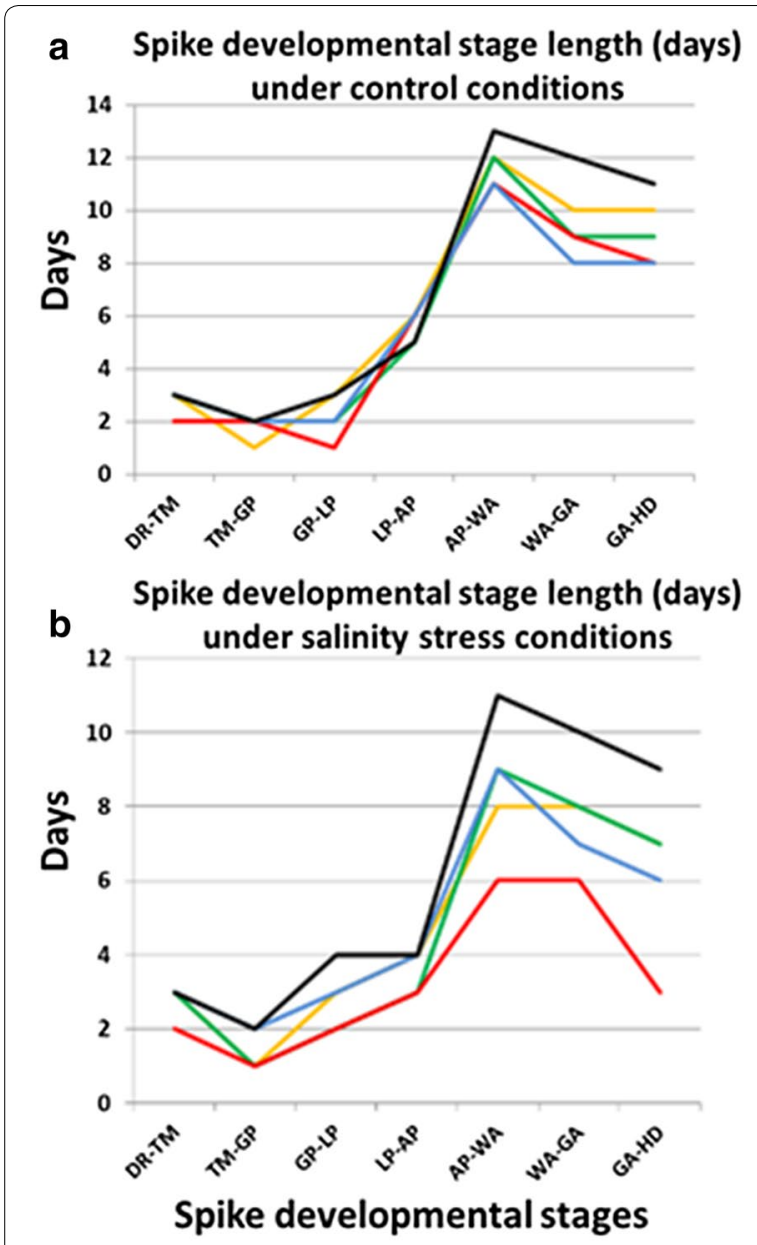

- Ardhaoui - Kounouz - Lemsi - Manel - Rihane

Fig. 3 Spike developmental stage length (Days) under control conditions (a) and salinity stress conditions (b). DR double ridge, TM triple mound, GP glume primordia, LP lemma primordium, AP awn primordium, WA white anther, GA green anther, HD heading

number of seeds/plant, plant seeds weight and 1000-seed weight (TSW) (Additional file 3: Table S2). Under control condition, the five genotypes showed no significant differences in seed width. Values for the other parameters differed, however. Spike lenght, seed length, and seed area were significantly larger in the genotypes Ardhaoui and Rihane and distinctly smallest in the Lemsi genotype. Furthermore, number of seeds/plant was lowest in the genotypes Ardhaoui and Kounouz and highest in the genotypes Manel, Lemsi and Rihane while TSW was higher in the genotypes Kounouz and Manel and lower in Ardhaoui, Lemsi and Rihane (Additional file 3: Table S2). In all five genotypes, salinity conditions caused a significant reduction in the traits spike length, seeds/plant and seed weight while the traits seed length, seed width and seed area were not significantly affected. Number of seeds/plant and seeds weight was highest in the genotype
Rihane and lowest in the genotype Lemsi. TSW was significantly reduced in the genotypes Ardhaoui and Lemsi, hardly affected in the genotypes Kounouz and Manel and significantly increased in the genotype Rihane. Overall, however, the negative effect of salinity treatment was strongest in the genotype Lemsi (Additional file 3: Table S2).

Under control conditions, data show different correlations between studied traits (Fig. 6a). Plant height was highly positive correlated with main spike length, seed area and seed length. Similarly, positive correlation was found for seed weight/plant which was highly correlated with TSW, seed width and number of seeds/plant. TSW was greatly correlated with seed width, the same for seed area and seed length, both correlations were positive. However, number of tillers/plant and seed length were negatively correlated with TSW and seed width. Under salinity stress treatment, new correlations between the traits comparing to control were detected (Fig. 6b). On the contrary of control conditions, plant height was positive correlated with number of seeds/plant and seed weight/plant, however, this positive correlation reduced with seed area and seed length. For main spike length, a negative correlation with number of seeds/plant and seeds weight/plant under control conditions turned into a positive correlation under salinity stress, a positive correlation with TSW was established. Number of seeds/ plant became negatively correlated with TSW and seed width, the positive correlation between number of seeds/ plant and seed weight/plant was more important under salt stress conditions than control. Regarding to seed area, two new positive correlations were generated under stress comparing to control.

\section{Discussion}

The study for the first time describes the effect of salinity stress (EC level $12.5 \mathrm{ds} / \mathrm{m}$ ) on spike developmental stages, spikelet primordia development and spike ABA concentrations in relation to yield in spring barley. The salinity caused reduction in the plant growth may be due to the negative effect of salt on many metabolic processes including protein nucleic acid and polyamine synthesis, transpiration, stomatal conductance, photosynthesis (Mittal and Dubey 1991; Reggiani et al. 1994; Netondo et al. 2004; Abbas et al. 2015; Bagues et al. 2018). Certain ions can restrict the absorption of water by plant roots (Mansour 1994; Ahmed et al. 2013), and/or induce an imbalance in phytohormone levels either through altered biosynthesis or a change in turn-over rates (Amzallage et al. 1992; Dunlap and Binzel 1996). Decreased plant height under the salinity might be due to the accumulation of salts in the cell wall limiting cell wall elasticity and cell elongation (Naseer et al. 2001; Taghipour and Salehi 

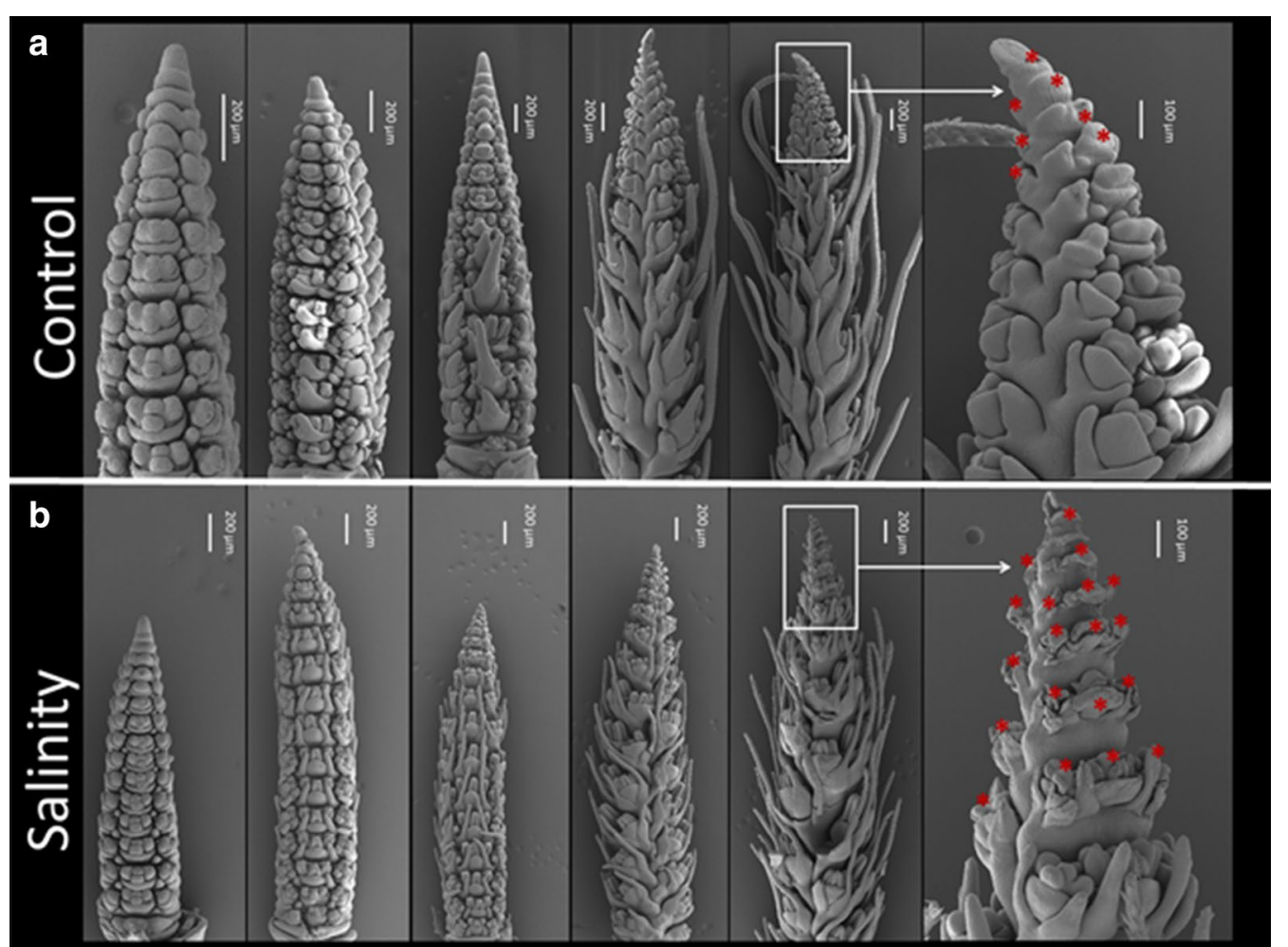

Fig. 4 Barley spike development under control (a) and salinity treatment (b) conditions. Red stars showed the undeveloped/later-aborted spikelets (color figure online)

2008; Colla et al. 2012) and resulting in stunted shoots (Aslam et al. 1993). Salinity stress also caused a significant reduction in number of tillers in all tested barley genotypes. These results concurred with the findings of Nicolas et al. (1994), Zhao et al. (2007), Shahzad et al. (2012) and Bagues et al. (2018).

Salinity treatment also had a direct effect on spike growth and spike development and through this an indirect effect on plant yield. We observed that under salinity treatment the spike developmental stages were shortened and degradation of spikelet primordia enhanced (Fig. 7). Although the underlying mechanisms are unclear, it is evident that under salinity stress the plant shortens its life cycle to rapidly produce a smaller number of seeds. Marschner (1971) reported that growing plants using saline water for irrigation affects physiological processes and reduces growth characters. Other studies have shown that the effect of salinity on yield components might be attributed to a rise in the osmotic pressure of rooting media which inhibits meristematic tissue activity and consequently leads to a reduction of the size and the number of cells per unit length (Thompson et al. 1997). Several authors have noted that salinity can inhibit plant growth by a range of mechanisms including osmotic effects which can restrict the absorption of water by plant roots, or direct ion toxicity and interference with the uptake of nutrients like $\mathrm{K}^{+}$(Aldesuquy 1991; Abd ElKarim 1996; Zhu et al. 1998).

In our previous study (Youssef et al. 2017) we described the hormonal role in regulating floral organ patterning and phase duration during barley inflorescence and shoot development. Spike development is mainly influenced by phytohormones such as IAA, CK and gibberellins (Pearce et al. 2013). Atrophy and degradation of spikelet primordia in the apical and basal sections of the spike during green anther stage are additional proof of a hormonal role in spike and spikelet/floret development. The high concentrations of ABA in these sections at GA stage cause a local inhibition of floret development (Wang et al. 2000). In the central part of the spike, however, the lower concentration of ABA found in this study and higher concentration of gibberellins (our previous study, Youssef et al. 2017) allows the development of fertile flowers and grain setting (Fig. 7). Similar results were also reported by Wang et al. (1999), Cao et al. (2000), Youssef et al. (2017) and Youssef and Hansson (2019). This ABA dependent modification of the grain number at the apical and basal parts of the spike could be the mechanism 

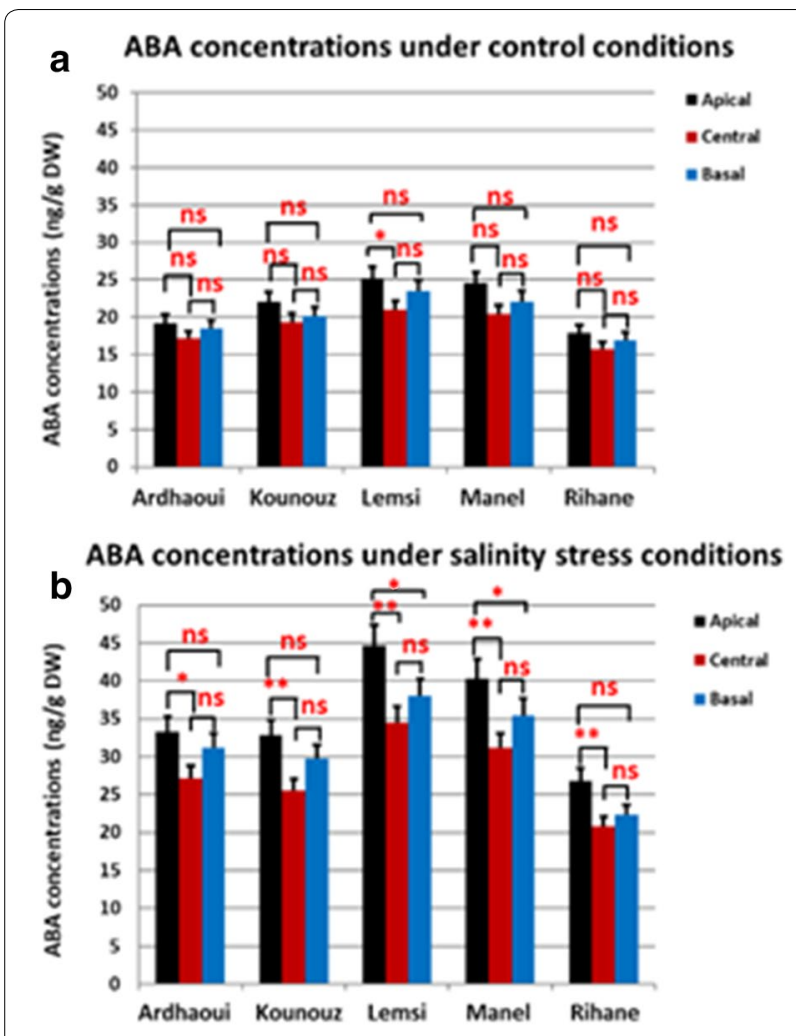

Fig. 5 ABA concentrations (ng/g DW) in apical, central and basal spike sections at green anther stage of the five spring barley genotypes under control (a) and salinity stress (b) conditions. *Significant $(P<0.05 \%)$. **High significant $(P<0.01)$. 'ns' 0 non-significant. Significant differences among the genotypes and the spike sections has been calculated using R 3.5.3 by which the barley spike adapts its yield potential. Atkinson et al. (2013) reported on a negative correlation between the susceptibility to abiotic stress (salinity and drought) and ABA concentrations. In accordance to this we found highest $A B A$ concentrations in the saline sensitive genotype Lemsi and lowest concentrations in the saline insensitive genotype Rihane (Fig. 5). In addition to the ABA effect, the spikelets/florets atrophy could be due to salt stress initially inducing osmotic stress and causing reduced water availability for the spikelets primordia, followed by ion toxicity due to nutrient imbalances in the cytosol causing spikelets/florets degradations and abortions.

In the present study, we also showed that salinity treatment adversely affects number of seeds/plant, weights of seeds/plant and TSW compared with the respective values in non-stressed control plants (Additional file 3: Table S2). The significant reduction in the grain yield under salt stress may be due to (i) an inhibition of tillering capacity (Fig. 2) causing a reduction in the number of spikes/plant as previously concluded by Al-Khafaf et al. (1990), Sakr et al. (2007) and Boussen et al. (2016), and (ii) enhanced degradation of the spikelet primordia through increasing of ABA concentrations in the apical and basal parts of the spikes (Figs. 4, 5, 7) reducing the number of seeds/spike. The detrimental and injurious effects of salinity on the growth productivity of barley shown here are in accordance with previous reports. Kumar et al. (1987) and Hank et al. (1989) showed that increasing salinity level in the irrigation water decreased growth and yield components of the plant. Holloway and Alston (1992) reported that salt stress decreased tillering,

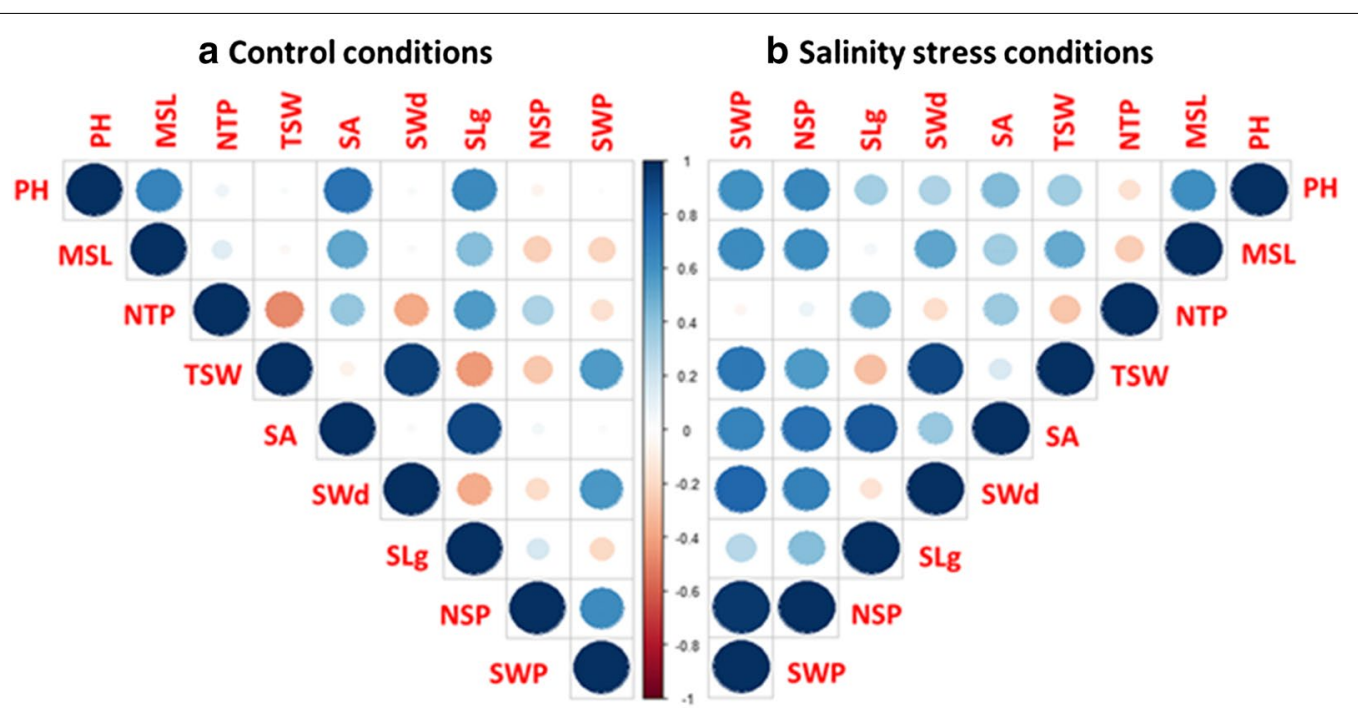

Fig. 6 Correlation matrix heatmap among the phenotypic and yield traits: PH plant height, MSL main spike length, NTP number of tillers/plant, TSW thousand seeds weight, SA seed area, SWd seed width, SLg seed length, NSP number of seeds/plant, SWP seeds weight/plant. Shades of blue indicate increasing positive correlation coefficient; shades of red indicate increasing negative correlation coefficient (color figure online) 


\section{a}

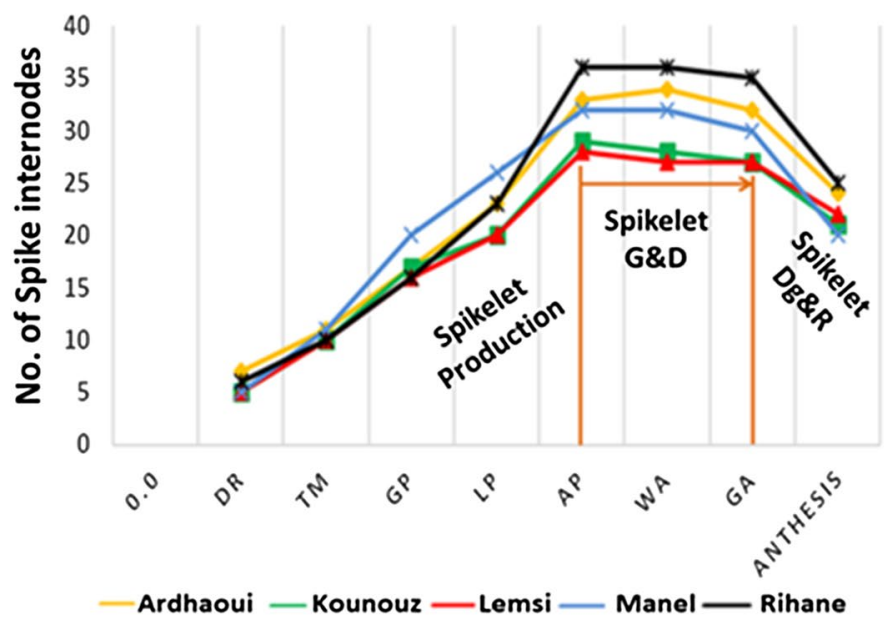

b

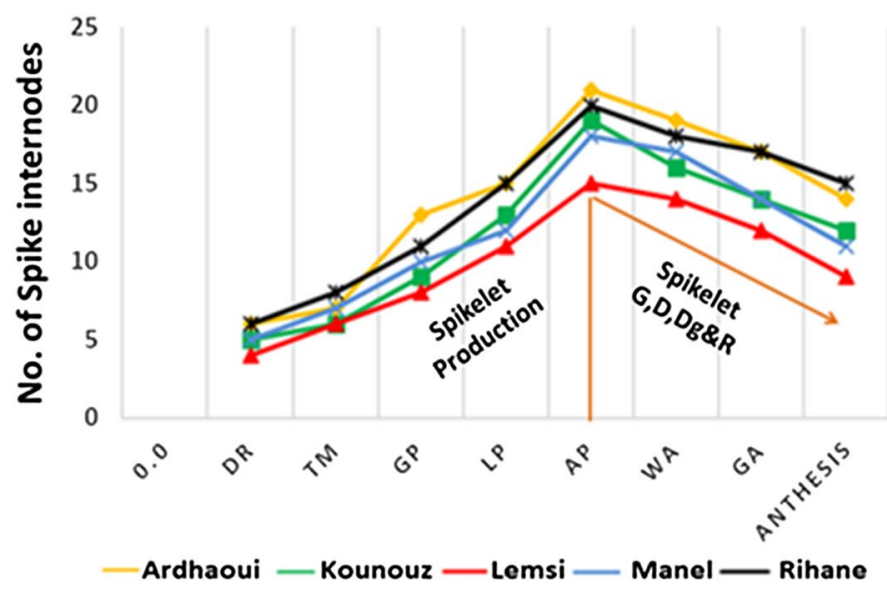

Spike developmental stages
ABA conc.
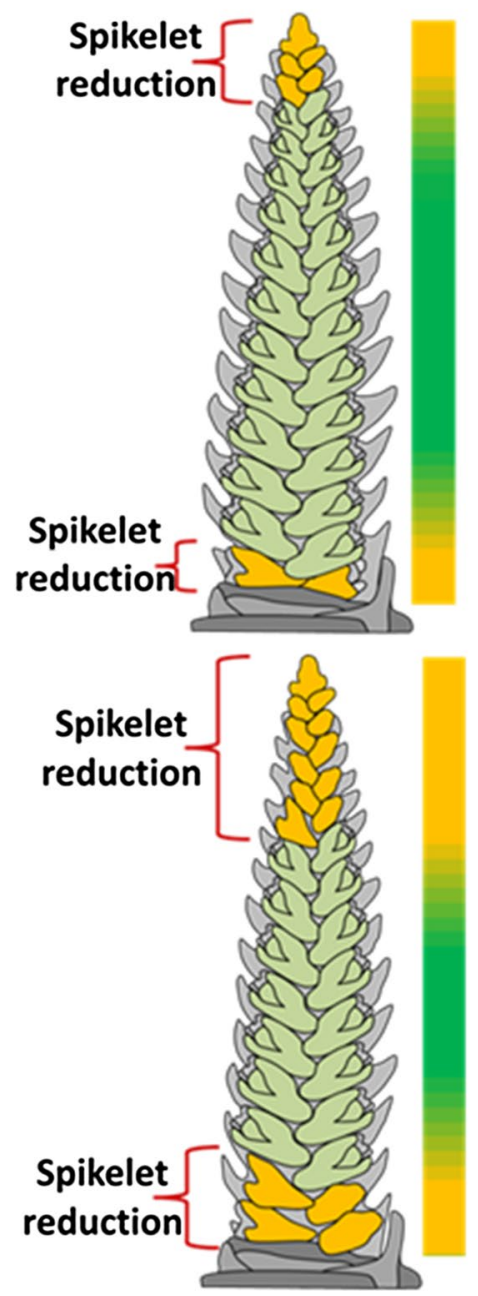

High ABA conc. Low ABA conc.

Fig. 7 Barley spikelet production, growth, development, degradation and reduction and ABA concentration in the immature spike in the five tested barley genotypes under control (a) and salinity stress (b) conditions. DR double ridge, TM triple mound, GP glume primordia, LP lemma primordium, $A P$ awn primordium, WA white anther, GA green anther, $G$ growth, $D$ development, $D g$ degradation, $R$ reduction

dry matter production and grain yield while Zeng and Shannon (2000) on rice and Sakr and El-Metwally (2009) on wheat, revealed that the reduction of tiller number/plant and spikelet number/panicle were the major causes of yield loss under salinity stress conditions. Sakr et al. (2004) suggested that the reduction in grain yield is largely due to a decrease in grain set which may be attributed to a decrease in the viability of pollen or in the receptivity of the stigmatic surface or both. Grattan et al. (2002) showed that salinity had negative impacts on number of spikes, tillers and spikelets per plant, floret sterility, individual grain size, and heading. We hypothesize that the reduction in grain yield of barley under salinity stress may be attributed to a diminished cell division and cell expansion in the spike, caused by altered concentrations of certain plant hormones like ABA. The ultimate result is a shortening of the spike developmental stages and a decreased production of developed spikelets and subsequent pollen grains. Hormones cross talking and their biological and genetic effects on spike and spikelet development appears a promising field for future work. 


\section{Conclusion}

Overall, salinity treatment reduced all yield-related parameters investigated and turned some of the correlations among them from positive to negative or vice versa. Investigations of $\mathrm{ABA}$ role in floral development and phase duration of barley spike showed that, ABA regulates the spikelet/floret abortion process affecting the yield potential under salinity and control conditions.

\section{Additional files}

Additional file 1: Fig. S1. Plant growth and phenotype under control (a) and salinity stress (b) conditions of the five tested barley genotypes Ardhaoui (G1), Kounouz (G2), Lemsi (G3), Manel (G4) and Rihane (G5). $\mathrm{C}=$ control, $\mathrm{T}=$ Treatment (salinity).

Additional file 2: Table S1. Effect of salinity stress treatment $(12.5 \mathrm{ds} / \mathrm{m})$ on spike developmental stages for the five tested barley genotypes.

Additional file 3: Table S2. Mean values of yield traits, spike length (cm), seed length $(\mathrm{mm})$, seed width $(\mathrm{mm})$, seed area $\left(\mathrm{mm}^{2}\right)$, number of seeds/ plant, seeds weight/plant (g) and 1000-seed weight (TSW) (g) for the five tasted barley genotypes under control and salinity treatment conditions.

\section{Abbreviations}

ABA: abscisic acid; GA: green anther; AP: awn primordium; Vrs: six-rowed-spike; IAA: auxin; CK: cytokinin; DR: double ridge; TM: triple mound; GP: glum primordia; SP: stamen primordium; LP: lemma primordium; WA: white anthers; HD: heading day; SEM: scanning electron microscopy; DAP: days after planting: TSW: 1000-seed weight; EC: electrical conductivity.

\section{Acknowledgements}

We thank the Aridlands and Oases Cropping Laboratory of Medenine, Tunisia, and IPK Genebank, Gatersleben, Germany for providing germ plasm for the study. We thank T. Schnurbusch for providing Stemi 2000-c, Carl Zeiss Micro Imaging $\mathrm{GmbH}$, Gottingen, Germany for doing spike developmental part of the work in his group. We also would like to thank the anonymous reviewers for their constructive and supportive evaluations while improving this manuscript. This work was supported by grants from the Tunisian national Ministry of Higher Education and Scientific Research and the University of Carthage to F.B.

\section{Authors' contributions}

$A B$ and $H M Y$ conceived and designed the research. FB, MA, FG, AF, TR and HMY performed experiments. FB, MA, HMY and MH analyzed data. FB, MA, $H M Y, M H$ and $A B$ wrote the manuscript with contributions from all coauthors. All authors read and approved the final manuscript.

\section{Funding}

This work was supported by grants from the Tunisian national Ministry of Higher Education and Scientific Research and the University of Carthage to F.B.

\section{Availability of data and materials \\ Not applicable.}

\section{Ethics approval and consent to participate}

Not applicable.

\section{Consent for publication}

Authors agree to the terms of the Springer Open Copyright and License Agreement.

\section{Competing interests}

The authors declare that they have no competing interests.

\section{Author details}

${ }^{1}$ Leibniz Institute of Plant Genetics and Crop Plant Research (IPK), Corrensstraße 3, 06466 Gatersleben, Germany. ${ }^{2}$ Faculty of Agriculture, Cairo University, Giza 12613, Egypt. ${ }^{3}$ Institute of Arid Lands of Medenine, Route du Djorf Km 22.5, Médénine, Tunisia. ${ }^{4}$ Faculty of Sciences of Bizerte (FSB), 7021 Zarzouna, Bizerte, Tunisia. ${ }^{5}$ Institut National Agronomique de Tunis, 43 Avenue Charles Nicolle, 1082 Tunis, Tunisia. ${ }^{6}$ Department of Biology, Lund University, Sölvegatan 35, 22362 Lund, Sweden. ${ }^{7}$ Institute of Agriculture, Lithuanian Research Centre for Agriculture and Forestry, Akademija, Lithuania.

Received: 21 May 2019 Accepted: 3 July 2019

Published online: 10 July 2019

\section{References}

Abbas G, Saqib M, Akhtar J, Haq MAU (2015) Interactive effects of salinity and iron deficiency on different rice genotypes. J Plant Nut Soil Sci 178:306-311

Abdel-Karim (1996) Studies on tolerance of some grape vine cultivars to stress. Ph.D. thesis Faculty of Agriculture Cairo University

Ahmed IM, Dai H, Zheng W, Cao F, Zhang G, Sun D, Wu F (2013) Genotypic differences in physiological characteristics in the tolerance to drought and salinity combined stress between Tibetan wild and cultivated barley. Plant Phys Biol 63:49-60

Albacete A, Ghanem ME, Martínez-Andújar C, Acosta M, Sánchez-Bravo J, Martínez V, Lutts S, Dodd IC, Pérez-Alfocea F (2008) Hormonal changes in relation to biomass partitioning and shoot growth impairment in salinized tomato (Solanum lycopersicum L.) plants. J Exp Bot 59:4119-4131

Aldesuquy HS (1991) Alleviation of salt stress on carbohydrate and nitrogen content of wheat flag leaf during filling by hormonal treatments. J Appl Sci 1:103-127

Al-Khaffaf S, Adnan A, Al-Asadi NM (1990) Dynamics of root and shoot growth of barely under various levels of salinity and water stress. Argic Water Manage 18:63-75

Alqudah A, Schnurbusch T (2014) Awn primordium to tipping is the most decisive developmental phase for spikelet survival in barley. Funct Plant Biol 41:424-436

Amzallage GN, Lerner HR, Poljakoff Mayber A (1992) Interaction between mineral nutrients, cytokinen and gibberellin during growth of sorghum at high $\mathrm{NaCl}$ salinity. J Exp Bot 43:81-87

Arisnabarreta S, Miralles DJ (2006) Yield responsiveness in two-and six-rowed barley grown in contrasting nitrogen environments. J Agric Crop Sci 192:178-185

Aslam MP, Qureshi RH, Ahmed N (1993) A rapid screening technique for salt tolerance in rice (Oryza sativa L.). Plant Soil 150:99-107

Atkinson NJ, Lilley CJ, Urwin PE (2013) Identification of genes involved in the response to simultaneous biotic and abiotic stresses. Plant Physiol 162:2028-2041

Bacon MA (1999) The biochemical control of leaf expansion during drought. Plant Grow Reg 29:101-112

Bacon MA, Wilkinson S, Davies WJ (1998) pH-regulated leaf cell expansion in droughted plants is abscisic acid dependent. Plant Physiol 118:1507-1515

Bagues M, Sarabi B, Ghashghaie J, Souli I, Nagaz K (2018) The validity of carbon isotope discrimination as a screening criterion for grain yield in two barley landraces under deficit irrigation with saline water in southern Tunisia. Plant Biotechnol 35:1-14

Basalah MO (2010) Action of salinity on seed germination and seedling growth of Solanum melongena L. J Agric Res Kafer El-Sheikh Univ 36:64-73

Ben Ghanem H, El Felah M (2011) Inscription d'une variété d'orge 'kounouz' dans le catalogue officiel Tunisien des obtentions végétales. Annales de I'INRAT 84:168

Ben Youssef S, El Felah M, Chakroun M (2011) Inscription d'une variété d'orge 'Lemsi' dans le catalogue officiel Tunisien des obtentions végétales. Annales de I'INRAT 84:171

Boussen H, Ben Salem M, Slama A, Mallek-Maalej E, Rezgui S (2016) Evaluation of drought tolerance indices in durum wheat recombinant inbred lines. https://www.researchgatenet/publication/268268090 
Bressan RA, Singh NK, Handa AK, Kononowicz A, Has-egawa PM (1985) Stable and unstable tolerance to $\mathrm{NaCl}$ in cultured tobacco cells. In: Freeling M (ed) Plant genetics. Liss, New York, pp 755-769

Cao WX, Wang Z, Dai TB (2000) Changes in levels of endogenous plant hormones during floret development in wheat genotypes of different spike sizes. J Integr Plant Biol 42:1026-1032

Chaabane R, El Faleh M, Ben Salah H, Ben Naceur M, Abdelly C, Ramla D, Nada A, Saker M (2009) Molecular Characterization of Tunisian Barley (Hordeum vulgare L.) genotypes using microsatellites (SSRs) markers. Eur I Sci Res 36:6-15

Colla E, Coune P, Liu Y, Pletnikova O, Troncoso JC, Iwatsubo T, Schneider BL, Lee MK (2012) Endoplasmic reticulum stress is important for the manifestations of a-synucleinopathy in vivo. J Neurosci 32:3306-3320

Collins JC, Kerrigan AP (1974) The effect of kinetin and abscisic acid on water and ion transport in isolated maize root. New Phytol 73:309-314

Cramer GR, Krishnan K, Abrams SR (1998) Kinetics of maize leaf elongation. IV. Effects of (+)- and (-)-absisic acid. J Exp Bot 49:191-198

Dai A (2011) Drought under global warming: a review. wiley interdisciplinary reviews. Clim Change 2:45-65

Davies WJ, Zhang J (1991) Root signals and the development of plants growing in drying soil. Ann Rev Plant Physiol Mol Biol 42:55-76

Dodd IC, Davies WJ (1996) The relationship between leaf growth and ABA accumulation in the grass leaf elongation zone. Plant Cell Environ 19:1047-1056

Du H, Wu N, Chang Y, Li X, Xiao J, Xiong L (2013) Carotenoid deficiency impairs ABA and IAA biosynthesis and differentially affects drought and cold tolerance in rice. Plant Mol Biol 83:475-488

Dunlap JR, Binzel ML (1996) NaCl reduces indol-3-acetil acid levels in the roots of tomato plants independent of stress-induced abscissic acid. Plant Physiol 112:379-384

Farooq M, Hussain M, Wakeel A, Siddique KHM (2015) Salt stress in maize: effects, resistance mechanisms, and management. A review. Agron Sustain Dev 35:461-481

Freundl E, Steudle E, Hartung W (2000) Apoplastic transport of abscisic acid through roots of maize: effect of the exodermis. Planta 210:222-231

Ghanem ME, Albacete A, Martínez-Andújar C, Acosta M, Romero-Aranda R, Dodd IC, Lutts S, Pérez-Alfocea F (2008) Hormonal changes during salinity-induced leaf senescence in tomato (Solanum lycopersicum L.). J Exp Bot 59:3039-3050

Ghassemi F, Jakeman AJ, Nix HA (1995) Salinisation of land and water resources: human causes, extent, management and case studies. UNSW, Sydney

Grattan SR, Zeng LH, Shannon MC, Roberts SR (2002) Rice is more sensitive to salinity than previously thought. California-Agriculture 56:189-195

Hanks RJ, Dundley LM, Cartee RL, Mace WR, Pomela E, Kidman RL, Wraith JM (1989) Use of saline waste water from electric power plants for irrigation. Report part 1. Soils irrigation water and crop yield studies. Res Rep Utah Agr Exp Statia 128:1-60

Holloway RE, Alston AM (1992) The effects of salt and boron on growth of wheat. Aust J Agric Res 43:987-1001

Hose E, Sauter A, Hartung W (2002) Abscisic acid in roots-biochemistry and physiology. In: Waisel Y, Eshel A, Kafkavi U (eds) Plant roots: the hidden half. Marcel Dekker Inc, New York, pp 435-448

Jamil A, Riaz S, Ashraf M, Foolad MR (2011) Gene expression profiling of plants under salt stress. Crit Rev Plant Sci 30:435-458

Kausar F, Shahbaz M, Ashraf M (2013) Protective role of foliar applied nitric oxide in Triticum aestivum under saline stress. Turk J Bot 37:1155-1165

Kernich GC, Halloran GM, Flood RG (1997) Variation in duration of pre-anthesis phases of development in barley (Hordeum vulgare). Aust J Agric Res 48:59-66

Kirby EJM, Appleyard M (1987) Development and structure of the wheat plant. In: Lupton FGH (ed) Wheat Breeding. Chapman \& Hall, London, pp 287-311

Kojima M, Kamada-Nobusada T, Komatsu H, Takei K, Kuroha T, Mizutani M, Ashikari M, Ueguchi-Tanaka M, Matsuoka M, Suzuki K, Sakakibara H (2009) Highly sensitive and high-throughput analysis of plant hormones using MS-probe modification and liquid chromatography-tandem mass spectrometry: an application for hormone profiling in Oryza sativa. Plant Cell Physiol 50:1201-1214
Kumar V, Kumar D, Singh SP, Chauchan CPS (1987) Response of bajra and wheat to different levels of nitrogen and phosphorus grown with saline water. Curr Agric 11:59-64

Läuchli A, Epstein E (1990) Plant responses to saline and sodic conditions. In: Tanji KK (ed) Agricultural salinity assessment and management. ASCE manuals and reports on engineering practice, vol 17. ASCE, New York, pp 113-137

Lee SC, Luan S (2012) ABA signal transduction at the crossroad of biotic and abiotic stress responses. Plant Cell Environ 35:53-60

Mansour MMF (1994) Changes in growth, osmotic potential and cell permeability of wheat cultivars under salt stress. Biol Plant 36:429-434

Marcum K, Pessarakli M (2006) Salinity tolerance and salt gland excretion efficiency of bermuda grass turf cultivars. Crop Sci 46:2571

Marschner P (1971) Mineral nutrition of higher plants. Academic Press, New York

Maslenkova LT, Zanev YU, Popova LP (1993) Adaptation to salinity as monitored by PSIl oxygen evolving reactions in barley thylakoids. J Plant Physiol 142:629-634

Matsoukas IG (2014) Interplay between sugar and hormone signalling pathways modulate floral signal transduction. Front Genet 5:218. https://doi. org/10.3389/fgene.2014.00218

Miralles DJ, Richards RA, Slafer GA (2000) Duration of the stem elongation period influences the number of fertile florets in wheat and barley. Aust J Plant Physiol 27:931-940

Mittal R, Dubey RS (1991) Influence of salinity on ribonuclease activity and status nucleic acids in rice seedling differing in salt tolerance. Plant Physiol Biochem 18:57-64

Moral GLF, Miralles DJ, Slafer GA (2002) Initiation and appearance of vegetative and reproductive structures throughout barley development. In: Slafer $J L$, Molina R, Savin JL, Araus DA, Romagosa I (eds) Barley science: recent advances from molecular biology to agronomy of yield and quality food products press. The Harworth Press, New York, pp 243-268

Munns R (2005) Genes and salt tolerance: bringing them together. New Phytol 167:645-663

Naseer S, Nisar A, Ashraf M (2001) Effect of salt stress on germination and seedling growth of barley (Hordeum vulgare L.). Pak J Biol Sci 4:359-360

Netondo GW, Onyango JC, Beck E (2004) Crop physiology and metabolism sorghum and salinity II—gas exchange and chlorophyll fluorescence of sorghum under salt stress. Crop Sci 44:806-811

Nicolas ME, Munns R, Samarakoon AB, Gifford RM (1994) Elevated CO2 improves the growth of wheat under salinity. Aust J Plant Physiol 20:349-360

Nilsen ET, Orcutt DM (1996) The physiology of plants under stress: abiotic factors. Wiley, New York, p 689

Okamoto M, Hanada A, Kamiya Y, Yamaguchi S, Nambara E (2009) Measurement of abscisic acid and gibberellins by gas chromatography/mass spectrometry. Methods Mol Biol 495:53-60. https://doi.org/10.1007/9781-59745-477-3_5

Owens S (2001) Salt of the earth. Genetic engineering may help to reclaim agricultural land lost due to salinization. EMBO Rep 2:877-879

Pearce S, Vanzetti LS, Dubcovsky J (2013) Exogenous gibberellins induce wheat spike development under short days only in the presence of vernalization. Plant Physiol 163:1433-1445

Pourkheirandish M, Komatsuda T (2007) The importance of barley genetics and domestication in a global perspective. Ann Bot 100:999-1008

R Core Team (2018). R: A language and environment for statistical computing. R Foundation for Statistical Computing, Vienna. https://www.R-proje ct.org/

Reggiani R, Aurisano N, Mattana M, Bertani A (1994) ABA induces 4-aminobutryrate accumulation in wheat seedlings. Phytochem 34:605-609

Riggs TJ, Kirby EJM (1978) Developmental consequences of two-row and six-row ear type in spring barley: 1. Genetical analysis and comparison of mature plant characters. J Agric Sci 91:199-205

Sakr MT, El-Metwally M (2009) Alleviation of the harmful effects of soil salt stress on growth, yield and endogenous antioxidant content of wheat plant by application of antioxidants. Pakistan J Biol Sci 12:624-630

Sakr MT, El-Hadidy M, Abo El-Kheer AM, Farouk S (2004) Physiological studies of some osmo-regulator on kanulla. International conversation microbiology and biotechnology in Africa and Arab Reagan 27th to 29th, pp 295-321 
Sakr MT, El-Emery ME, Fouda RA, Mowafy MA (2007) Role of some antioxidants in alleviating soil salinity stress. J Agric Sci Mansoura Univ 32:9751-9763

Sarabi B, Bolandnazar S, Ghaderi N, Ghashghaie J (2017) Genotypic differences in physiological and biochemical responses to salinity stress in melon (Cucumis melo L.) plants: prospects for selection of salt tolerant landraces. Plant Physiol Biochem 119:294-311

Seo M, Jikumaru Y, Kamiya Y (2011) Profiling of hormones and related metabolites in seed dormancy and germination studies. In: Kermode RA (ed) Seed dormancy: methods and protocols. Humana Press, Totowa, pp 99-111

Shahzad A, Ahmad M, Iqbal M, Ahmed I, Ali GM (2012) Evaluation of wheat landrace genotypes for salinity tolerance at vegetative stage by using morphological and molecular markers. Genet Mol Res 11:679-692

Shannon MC (1984) Breeding, selection and the genetics of salt tolerance. In: Staples RC, Toenniessen GH (eds) Salinity tolerance in plants: strategies for crop improvement. Wiley, New York, pp 231-254

Su YH, Liu YB, Zhang XS (2011) Auxin-cytokinin interaction regulates meristem development. Mol Plant 4:616-625

Suzuki N, Bassil E, Hamilton JS, Inupakutika MA, Zandalinas SI, Tripathy D, Luo Y, Dion E, Fukui G, Kumazaki A, Nakano R, Rivero RM, Verbeck GF, Azad RK, Blumwal E, Mittler R (2016) ABA is required for plant acclimation to a combination of salt and heat stress. PLOS ONE 11:e0147625

Taghipour F, Salehi M (2008) The study of salt tolerance of Iranian barley (Hordeum vulgare L.) genotypes in seedling growth stages. Am-Eur J Agric Environ Sci 4:525-529

Thompson DS, Wilkinson S, Bacon MA, Davies WJ (1997) Multiple signals and mechanisms that regulate leaf growth and stomatal behaviour during water deficit. Physiol Planta 100:303-313

Torech FR, Thompson LM (1993) Soils and soil fertility. Oxford University Press, New York

Waddington SR, Cartwright PM, Wall PC (1983) A quantitative scale of spike initial and pistil development in barley and wheat. Ann Bot 51:119-130

Wang R, Yu Z, Pan Q, Xu Y (1999) Changes of endogenous plant hormone contents during grain development in wheat. Zuo Wu Xue Bao 25:227-231
Wang Z, Cao W, Dai T, Zhou Q (2000) Effects of exogenous hormones on floret development and grain set in wheat. Plant Growth Regul 35:222-231

Whingwiri EE, Stern WR (1982) Floret survival in wheat: significance of the time of floret initiation relative to terminal spikelet formation. J Agric Sci (Camb) 98(25):268

Wilkinson S, Davies WJ (2010) Drought, ozone, ABA and ethylene: new insights from cell to plant to community. Plant Cell Environ 33:510-525

Willenborg CJ, Gulden RH, Johnson EN, Shirtliffe SJ (2004) Germination characteristics of polymer-coated canola (Brassica napus L.) seeds subjected to moisture stress at different temperatures. AgroJournal 96:786-791

Wu Y, Kuzma J, Maréchal E, Graeff R, Lee HC, Foster R, Chua NH (1997) Abscisic acid signaling through cyclic ADP-ribose in plants. Science 19:2126-2130

Youssef HM, Hansson M (2019) Crosstalk among hormones in barley spike contributes to the yield. Plant Cell Rep 1:1. https://doi.org/10.1007/s0029 9-019-02430-0

Youssef HM, Eggert K, Koppolu R, Alqudah AM, Poursarebani N, Fazeli A, Sakuma S, Tagiri A, Rutten T, Govind G et al (2017) VRS2 regulates hormone-mediated inflorescence patterning in barley. Nat Genet 49:157-161

Zeng L, Shannon MC (2000) Effects of salinity on grain yield and yield components of rice at different seeding densities. Agron J 92:418-423

Zhao GQ, Ma BL, Ren CZ (2007) Growth, gas exchange, chlorophyll fluorescence and ion content of naked oat in response to salinity. Crop Sci 47:123-131

Zhu B, Su J, Chong M, Verma DPS, Fare Y, Wu R (1998) Over expression of $\triangle$-pyrolline-5-carboxylate synthetase gene and analysis of tolerance to water- and salt-stress in transgenic rice. Plant Sci 139:41-48

\section{Publisher's Note}

Springer Nature remains neutral with regard to jurisdictional claims in published maps and institutional affiliations.

\section{Submit your manuscript to a SpringerOpen ${ }^{\circ}$ journal and benefit from:}

- Convenient online submission

- Rigorous peer review

- Open access: articles freely available online

- High visibility within the field

- Retaining the copyright to your article

Submit your next manuscript at $\boldsymbol{\Delta}$ springeropen.com 